\title{
Efficacy of Mosquito Repellent and Adulticidal Activities of Halophila Ovalis Extract Against Filaria Vectors \\ Anuradha $\mathbf{V}^{1}$, Syed Ali $\mathbf{M}^{2^{*}}$, Yogananth $\mathbf{N}^{2}$
}

${ }^{1} P G$ \& Research Department of Biochemistry, Mohamed Sathak College of Arts \& Science, Sholinganallur, Chennai, Tamilnadu, India ${ }^{2}$ Department of Biotechnology, Mohamed Sathak College of Arts \& Science, Sholinganallur, Chennai, Tamilnadu, India

\begin{abstract}
The repellent and adulticidal activities were analyzed for ethanol extract of Halophila ovalis against Culex quinquefasciatus ( $C x$. quinquefasciatus). The extraction was done in soxhlet apparatus using ethanol as solvent. The repellent activity of the Halophila ovalis was determined against Culex quinquefasciatus in different concentration of the extract at 100,150,200, 250 and $300 \mu \mathrm{L} / \mathrm{cm}^{2}$. Adulticidal activity of the Halophila ovalis extract was tested against four to five day old female adults of Culex quinquefasciatus. The adult mortality was observed $24 \mathrm{~h}$ under the laboratory conditions. Each experiment was conducted with the three replicates and a concurrent control group. As per the WHO guidelines, the experiments were conducted. At $250 \mu \mathrm{L}$ of concentration extracts of Halophila ovalis showed maximum repellency percentage of $95 \%$ against Culex quinquefasciatus. The highest adulticidal activity was observed in $100 \mu \mathrm{L}$ concentration against Culex quinquefasciatus with $\mathrm{LC}_{50}$ were $(50.2 \pm 0.7) \mu \mathrm{L} / \mathrm{ml}$ and $(51.2 \pm 0.9) \mu \mathrm{L} / \mathrm{ml}$. The GC-MS reveals unique chemical compounds obtained from the extract of Halophila ovalis. The present study identifies the active insecticidal compounds from Halophila ovalis by GC-MS and from the results it can be concluded the extract of Halophila ovalis can be novel efficient biocontrol source against filariasis mosquitoes.
\end{abstract}

Keywords: Halophila ovalis; Culex quinquefasciatus; Mosquito; Repellent

\section{Introduction}

Mosquito vectors are essential for understanding vector-borne disease transmission dynamics among human populations because patterns of genetic structure and pathogen transfer through vector populations [1,2]. In India alone 25 million people suffer from filariasis [3]. Dengue is prevalent in more than 100 countries and threatens the health of approximately 2.5 billion people. Around 80 million people are infected annually at an attack rate of $4 \%$ worldwide [4]. The mosquito control continues to be an important strategy in preventing the mosquito-borne diseases [5]. Diseases that are healthcare associated transmission of viruses to human from mosquitoes are an expanding problem in tropical and subtropical regions [6]. Currently, most insecticides are non-selective and can be harmful to other organisms and to the environment [7]. The activity of crude plant extracts is often attributed to the complex mixture of active compounds [8]. Repeated use of synthetic insecticides for mosquito control has disrupted natural biological control systems and led to resurgences in mosquito populations [9]. In view of the residue problems in the environment and development of insect resistance to synthetic insecticides like DDT and chlorinated hydrocarbons [10]. Development of resistance to commercial acaricides by parasites has stimulated the search for new control strategies [11]. Plant parts have been provided as a good source of novel drug compounds [12]. However, mosquitoes have successfully adapted to most plant based insecticides by becoming physiologically or behaviorally resistant to them [13]. Marine biodiversity provides important sources of chemical compounds, which have many therapeutic applications such as antimicrobial, infertility and anticancer activities [14]. Seagrasses are one of the most important marine resources of the world and being used as animal feed and raw material for many industries. For centuries, seagrass has been of botanical and pharmaceutical interest [15]. Various surveys have shown that seaweeds are an excellent source of constituents such as polysaccharides, tannins, flavonoids, phenolic acids, bromophenols, carotenoids and exhibited different biological activities [16]. The objective of this present study was to evaluate larvicidal, repellent and adulticidal activities of Halophila ovalis extracts against Culex quinquefasciatus.

\section{Materials and Methods}

\section{Plant materials}

Fresh sample of Halophila ovalis was collected from Mandapam, Ramanathapuram District, Tamil Nadu of south east coast of India (Latitude $9^{\circ} 45^{\prime} \mathrm{N}$ and longitude $79^{\circ} 13^{\prime} \mathrm{E}$ ). The collected samples were washed in seawater to remove sand, mud and all epiphytes, thrice with tap water and twice with distilled water to remove the adhering salts. The samples were dried at room temperature and were ground separately into powder using a miller before extraction of the crude seaweed extract.

\section{Extract preparation}

The seagrass powder was boiled in ethanol and distilled water mixture $(7: 3 \mathrm{v} / \mathrm{v})$ at $55^{\circ} \mathrm{C}$ for $2 \mathrm{~h}$ using a soxhlet apparatus under reduced pressure. The filtrate was condensed by evaporating to a minimal volume at $45^{\circ} \mathrm{C}$ and then freeze-dried $\left(-80^{\circ} \mathrm{C}\right)$. The extract obtained was referred to as crude seaweed extract. The percentage of extraction was calculated by using the following formula,

$$
\text { Weight of the extract }
$$

Percent of extraction $=$ $\times 100$

\section{Weight of the plant material}

The extract preparation was done by following the method of Ali et al., [12] with slight modification.

${ }^{*}$ Corresponding author: Syed Ali M, PG \& Research Department of Biotechnology Mohamed Sathak College of Arts \& Science, Sholinganallur, Chennai, Tamilnadu, India, Tel: 00919842052929; E-mail: syedmicro555@gmail.com

Received November 04, 2015; Accepted December 07, 2015; Published December 14, 2015

Citation: Anuradha V, Syed Ali M, Yogananth N, (2015) Efficacy of Mosquito Repellent and Adulticidal Activities of Halophila Ovalis Extract Against Filaria Vectors. J Trop Dis 4: 191. doi:10.4172/2329-891X.1000191

Copyright: (c) 2015 Anuradha V, et al. This is an open-access article distributed under the terms of the Creative Commons Attribution License, which permits unrestricted use, distribution, and reproduction in any medium, provided the original author and source are credited. 


\section{Mosquito larval culture}

Mosquito larva of Culex quinquefasciatus were collected from our college (Mohamed sathak college of arts and science, sholinganallur, Chennai) sewage water, placed in dechlorinated water in separate plastic trays. They were reared indoors at $(28 \pm 2){ }^{\circ} \mathrm{C}$ and $75-85 \%$ relative humidity under 14:10 light and dark period cycle. The larvae were fed with powdered mix of dog biscuits and brewer's yeast powder in 3:1 ratio. Pupae were transferred from the trays to a cup containing tap water and were maintained in cages $(45 \times 45 \times 40 \mathrm{~cm})$ where adults emerged. After five days emergence, female mosquitoes were moved into a mosquito cage where the emerging adults were fed with a $10 \%$ sucrose solution in air- tight cylindrical glass container with a cotton wick. Glass Petri dishes with $50 \mathrm{ml}$ of tap water lined with filter paper were kept inside the cage for oviposition. The Mosquito larval culture was done by following with slightly modified the method of Ali et al. [14].

\section{Repellent activity}

The repellent activity was conducted with slightly modified as per the method of Syed Ali et al., [10] and was determined by the percentage protection time in relation to dose method WHO [17]. Repellency bioassays were carried out in a $10 \times 10 \times 3 \mathrm{~m}$ room at $27-35^{\circ} \mathrm{C}$ and $60-80 \% \mathrm{RH}$. The target Culex quinquefasciatus, the testing period was run between 0-6 h. Three to four days old blood-starved 100 adult females of Culex quinquefasciatus mosquito was randomly selected and placed in an experimental cage $(30 \times 30 \times 30 \mathrm{~cm})$ and left to acclimatize for $1 \mathrm{~h}$. The arm tested person was cleaned with ethanol. After air drying the arm of the test person, only $25 \mathrm{~cm}^{2}$ dorsal side of the skin on each arm was exposed and the remaining area being covered with rubber gloves. The ethanolic seagrass extract of Halophila ovalis with different concentration $(100 \mu \mathrm{L}, 150 \mu \mathrm{L}, 200 \mu \mathrm{L}, 250 \mu \mathrm{L})$ was applied. The control and treated arms were introduced simultaneously into the cage. The first bite by Culex quinquefasciatus was noted from 5 minutes for every $1 \mathrm{~h}$ upto $6 \mathrm{~h}$. Subsequently, the test arm was introduced into the cage for the same period of time and the numbers of mosquitoes that landed and attempted to feed were recorded. The experiment was conducted for three times. It was observed that there was no skin irritation by the extracts of Halophila ovalis. The percentage protection was calculated by using the following formula;

No. of bites received by control - No. of bites received by treated

Percentage Protection $=$ $\times 100$

No. of bites received by control

\section{Adulticidal activity}

The repellent activity was conducted with slightly modified as per the method of Govindarajan et al. [13] and was determined by the percentage mortality rate in relation to dose method WHO $[18,19]$. The toxicity of the ethanolic extract derived from seagrass against four to five days old female adults of Aedes aegypti and Culex quinquefasciatus was examined. Glass tubes of $20 \mathrm{ml}$ capacity were used as exposure chambers during the fumigation test. The ethanolic seaweed extract was applied on Whatman no. 1 filter paper $\left(12 \times 15 \mathrm{~cm}^{2}\right)$ placed inside the glass tubes at concentrations of $(100 \mu \mathrm{L}, 150 \mu \mathrm{L}, 200 \mu \mathrm{L})$ of extracts. The extract papers were rolled and placed in exposure tubes, the hole on the top of the tube sucrose fed and blood starved 20 mosquito adults was allowed inside and plugged with cotton. They kept for acclimatize for $1 \mathrm{hr}$ and fumigated adults were observed and tabulated. A pre dried Whatman no. 1 filter paper consists ethanol added was served as control. At the end of exposure the mosquitoes were placed in holding glass tube. Cotton pads soaked in $10 \%$ sugar solution with vitamin B complex were placed during the holding period of $24 \mathrm{~h}$. The number of dead mosquitoes and mortality percentages were determined after 24 hrs of treatment. Triplicates of each treatment and control were set up.

\section{GC-MS analysis}

GC-MS technique was used to examine the constituents of extracts from $H$. Ovalis was carried out in IITM, Tamil Nadu. It was performed using Agilent and Jeol GC mateII (Mass spectrometry) by HP- 5 column capillary equipped with a high temperature column (DB-5 mm $30 \times$ $0.25 \mathrm{~mm} \times 0.25 \mu \mathrm{m})$ was used and works with $70 \mathrm{eV}$. The injector and detector temperature can set at $250^{\circ} \mathrm{C}$. A $1 \mu \mathrm{L}$ sample volume was injected into the column and employed using split less mode. High pure Helium is carrier gas was programmed to maintain a constant flow rate of $1 \mathrm{ml} / \mathrm{min}$. The column oven temperature was initially kept at $80^{\circ} \mathrm{C}$ for $2 \mathrm{~min}$, then programmed at $200^{\circ} \mathrm{C} / \mathrm{min}$, which was held at 20 min. Identification of organic compound was matching their recorded spectra with the data bank mass spectra of NIST library provided by the instrument.

\section{Statistical analysis of data}

The average mortality data were subjected to profit analysis to calculate $\mathrm{LC}_{50}$ and $95 \%$ fiducial limits of upper confidence limit (UCL) and lower confidence limit (LCL), regression equation, Chi-square and analysis variation values were calculated using the Stat plus 2009 software. Results with $\mathrm{p} \leq 0.05$ were considered to be statistically significant.

\section{Results and Discussion}

The in a progress study have tested with marine seagrass extract of Halophila ovalis (Figure 1) against the vector borne disease causing mosquito like Culex quinquefasciatus. It reveals that the extract of Halophila ovalis showed various ranges of repellent and adulticidal activities. Halophila ovalis showed the maximum percentage of showed protection percentage of Culex quinquefasciatus mosquito protection (95) and protection time (4.4 hrs) was observed at the 250 $\mu \mathrm{L}$ of Halophila ovalis extract. The results were presented in Table 1. However, bites were observed between 10.00-16.00 hrs with the remaining concentration of extract treated arms. The result of the adulticidal activity from Halophila ovalis against Culex quinquefasciatus are presented in Table 2. Among the five concentrations of seaweed extract tested, the highest adulticidal activity was observed in $200 \mu \mathrm{L}$ against Culex quinquefasciatus with the $\mathrm{LC}_{50}=51.2 \pm 0.9$ and LCL-UCL values of, 50.2-56.8 respectively, and the regression value $\mathrm{R}^{2}=0.959$ and analysis of variation was significant at $\mathrm{p} \leq 0.05$ level. The relative percentage of identifying compounds from the ethanolic extract of Halophila ovalis were depicted in Table 3 were Hexadecanoic acid, followed by Glucobrassicin, Ethanol, 2-(9-octadecenyloxy)-,(Z), Ethanone, 1,1'-(1,4-dihydro-2,4,6-trimethyl-3,5-pyridinediyl)bis. , Tridecanoic acid, methyl ester, 1,2,4-Trioxolane-2-octanoic acid, 5-octyl-, Methyl ester, Pentetic Acid and 9-Hexadecenoic acid.

The studies on mosquito larvicidal activities with seaweed extracts are too restricted. The seaweed extract of Halophila ovalis showed significant repellent and adulticidal activities. The results were comparable with early studies of Ali et al., reported the seaweed extract, C. racemosa showed toxicity against 4th instar larvae of Aedes aegypti, Culex quinquefasciatus, Anopheles stephensi with equivalent $\left(\mathrm{LC}_{50}=0.0556 \pm 0.0103 \mu \mathrm{g} / \mathrm{mL}, 0.0675 \pm 0.1360 \mu \mathrm{g} / \mathrm{mL}\right.$ and $0.0661 \pm$ $0.0076 \mu \mathrm{g} / \mathrm{mL}$ ) respectively [12]. Ali et al., [10] reported that column chromatographic fractions of $R$. mucronata bark extracts (E1) showed 


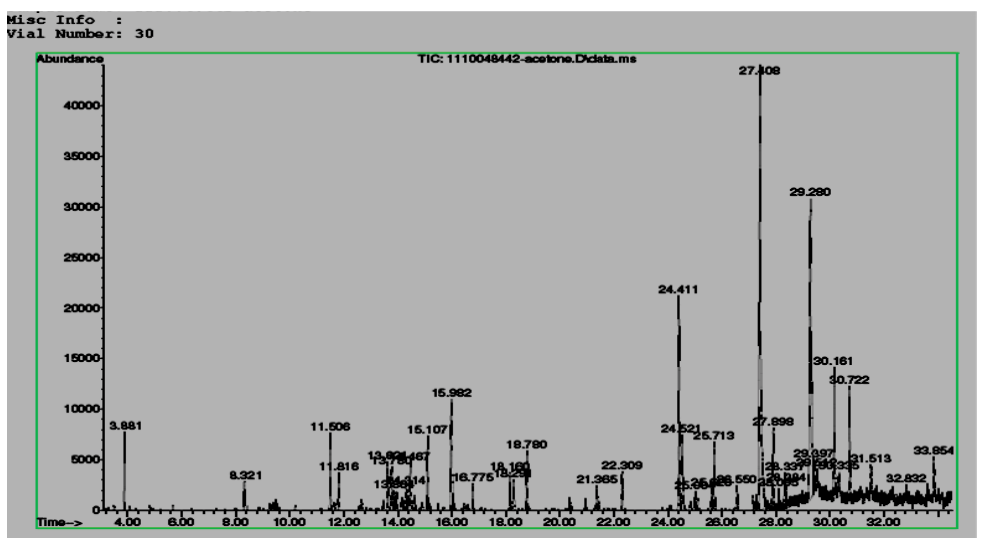

Figure 1: GCMS analysis of seagrass extract of $H$. ovalis.

\begin{tabular}{|c|c|c|c|c|c|c|c|c|c|c|c|c|c|c|}
\hline \multirow{3}{*}{$\begin{array}{c}\text { Concentration } \\
(\%)\end{array}$} & \multicolumn{12}{|c|}{ Treatments Period (hrs) } & \multirow{3}{*}{$\%$ of protection } & \multirow{3}{*}{$\begin{array}{l}\text { Protection } \\
\text { Time (hrs) }\end{array}$} \\
\hline & \multicolumn{2}{|c|}{$10-11$} & \multicolumn{2}{|c|}{$11-12$} & \multicolumn{2}{|c|}{$12-13$} & \multicolumn{2}{|c|}{$13-14$} & \multicolumn{2}{|c|}{$14-15$} & \multicolumn{2}{|c|}{$15-16$} & & \\
\hline & $\mathrm{T}$ & C & $\mathrm{T}$ & C & $\mathrm{T}$ & C & $\mathrm{T}$ & C & $\mathrm{T}$ & C & $\mathrm{T}$ & C & & \\
\hline 100 & 0 & 0 & 0 & 0 & 3 & 5 & 4 & 7 & 3 & 9 & 3 & 10 & 59.3 & 1.2 \\
\hline 150 & 0 & 0 & 0 & 1 & 2 & 5 & 2 & 7 & 3 & 9 & 4 & 10 & 65.6 & 1.5 \\
\hline 200 & 0 & 0 & 0 & 1 & 1 & 4 & 2 & 6 & 2 & 9 & 3 & 11 & 74.1 & 2.1 \\
\hline 250 & 0 & 0 & 0 & 3 & 0 & 5 & 1 & 8 & 2 & 10 & 3 & 11 & 95 & 4.4 \\
\hline
\end{tabular}

T-Treatment, C-Control

Table 1: Repellent activity of ethanolic seagrass extract of $H$. ovalis against $C$. Quinquefasciatus.

\begin{tabular}{|c|c|c|c|c|}
\hline \multirow{2}{*}{ No. of Mosquito } & Concentration $(\mu \mathrm{L})$ & \multicolumn{2}{|c|}{ LC $_{50}(\mathrm{mg} / \mathrm{ml})$} & \multicolumn{2}{|c|}{$\mathrm{P} \leq 0.05$} \\
\cline { 2 - 4 } & & Mean \pm SE & $29.6-34.9$ & 1.048 \\
\hline 25 & 100 & $32.6 \pm 0.58$ & $43.1-46.1$ & 1.125 \\
\hline 25 & 150 & $45.1 \pm 0.25$ & $50.2-56.8$ & $0.959 *$ \\
\hline
\end{tabular}

*Significant at $\mathrm{P}<0.05$ level, LCL: Lower confidence level, UCL: Upper confidence level, $\mathrm{R}^{2}$ - Regression equation of significant level of $\mathrm{P} \leq 0.05$

Table 2: Adulticidal activity from seagrass extract of $H$. ovalis against $C$. quinquefasciatus.

\begin{tabular}{|c|c|c|c|}
\hline Retention time & Compound & Molecular weight & Peak Area \\
\hline 11.67 & Hexadecanoic acid & 256.42 & 15272544 \\
\hline 12.63 & Glucobrassicin & 447.46 & 5986464 \\
\hline 15.33 & Ethanol, 2-(9-octadecenyloxy)-,(Z) & 312.53 & 7423168 \\
\hline 15.45 & Ethanone, $1,1^{\prime}$-(1,4-dihydro-2,4,6-trimethyl-3,5-pyridinediyl)bis- & 165.18 & 7269504 \\
\hline 15.07 & Tridecanoic acid, methyl ester & 228.37 & 7721632 \\
\hline 56.23 & 1,2,4-Trioxolane-2-octanoic acid, 5-octyl-, methyl ester & 344.48 & 6614032 \\
\hline 73.33 & Pentetic Acid & 393.35 & 5986464 \\
\hline 56.23 & 9-Hexadecenoic acid & 254.40 & 8790688 \\
\hline
\end{tabular}

Table 3: Identification of compound from seagrass extract of $H$. ovalis using GCMS.

maximum larvicidal activity $\left(\mathrm{LC}_{50}=0.0496 \pm 0.0085 \mu \mathrm{g} / \mathrm{ml}\right.$ and $\mathrm{LC}_{90}=$ $0.1264 \pm 0.052 \mu \mathrm{g} / \mathrm{ml})$, acetone extract $\left(\mathrm{LC}_{50}=0.0564 \pm 0.0069 \mu \mathrm{g} / \mathrm{ml}\right.$ and $\mathrm{LC}_{90}=0.1187 \pm 0.05 \mu \mathrm{g} / \mathrm{ml}$ ), ethanolic fraction (E4) of $R$. mucronata stilt root extracts showed maximum larvicidal activity $\left(\mathrm{LC}_{50}=0.0484 \pm\right.$ $0.0078 \mu \mathrm{g} / \mathrm{ml}$ and $\left.\mathrm{LC}_{90}=0.1191 \pm 0.025 \mu \mathrm{g} / \mathrm{ml}\right)$ and acetone fraction (A3) $\left(\mathrm{LC}_{50}=0.0419 \pm 0.0059 \mu \mathrm{g} / \mathrm{ml}\right.$ and $\left.\mathrm{LC}_{90}=0.0955 \pm 0.069 \mu \mathrm{g} / \mathrm{ml}\right)$. Kovendan et al. [11] evaluated $\mathrm{LC}_{50}$ values of hexane, chloroform, ethyl acetate, acetone and methanol extract of $O$. thymiflorus third instar larvae of An. stephensi were $\mathrm{LC}_{50}=201.39,178.76,158.06,139.22$ and $118.74 \mathrm{ppm}$; $C x$. quinquefasciatus were $\mathrm{LC}_{50}=228.13,209.72,183.35,163.55$ and 149.96 ppm and Ae. aegypti were $\mathrm{LC}_{50} 215.65,197.91,17505,154.80$ and 137.26 ppm respectively. Several authors have investigated that ethanolic extract show mosquito larvicidal activity [10,12]. Similarly, the present study was made an attempt and against $C$. quinquefasciatus were observed at maximum activity of minimum concentration at $250 \mu \mathrm{L}$.

Today, worldwide consumption of synthetic repellents has increased to prevent losses in store foodstuff materials. Unlike the larvicides, mosquito repellents only reduce the bites and cannot be considered as a control measure. Investigated Chloroform: methanol of mature leaf extract of $S$. mahagoni exhibits $100 \%$ repellency up to $2 \mathrm{~h} 15 \mathrm{~min}$ as no mosquito bites up to that time periods in the treated hands [20]. Ali et al., [10] reported repellency of $R$. mucronata done 
in stilt root and bark extracts (A3) showed maximum protection (97.5\%) with $9.1 \mathrm{~h}$ protection time at $4 \mathrm{mg}$ concentration and ethanolic fraction of the stilt root (E4) extract showed maximum (100\%) with 10 $\mathrm{h}$ protection time at $4 \mathrm{mg}$ concentration. Plant based insecticides are nontoxic, easily available and show target specific activities. Kamaraj et al., [21] observed maximum repellent activity was observed at $500 \mathrm{ppm}$ in methanol extracts of $N$. nucifera, ethyl acetate and methanol extract of $P$. nigrum and methanol extract of T. ammi protection time from 30 to $150 \mathrm{~min}$. Chemical repellents are not secure for public consume due to their apparent toxicity. Many researchers proved phytochemical constituents such as n-Hexadecanoic acid, Furfural, Glucobrassicin acts as insecticidal agents. Marimuthu Govindarajan et al evaluated the methanol extract of $E$. alba and A. paniculata was produced maximum repellency against An. Stephensi [22]. Skin repellent test by Pushpanathan et al, at $1.0,2.5$ and $5.0 \mathrm{mg} / \mathrm{cm}^{2}$ concentration of C. citratus gave $100 \%$ protection up to $3.00,4.00$ and 5.00 hours respectively. Likewise, the repellency percentage of $95 \%$ against $C$. quinquefasciatus at $250 \mu \mathrm{L}$ of concentration extract of Halophila ovalis was determined in the present study.

The plant produces a great array of secondary metabolites as a result of metabolic activities. These compounds either alone or in combination are responsible for the specific therapeutic action administered as a medicament or a health supplement. Kovendan et al., [6] reported the adult mortality was found in ethanol extract of $C$. sinensis with the $\mathrm{LC}_{50}$ and $\mathrm{LC}_{90}$ values of 272.19 and $457.14 \mathrm{ppm}, A$. stephensi; 289.62 and 494.88 ppm, Ae. aegypti; and 320.38 and 524.57 ppm, respectively. Comparatively, the adulticidal activity was observed in $200 \mu \mathrm{L}$ concentration against $C x$. quinquefasciatus with $\mathrm{LC}_{50}(51.2 \pm$ $0.9) \mu \mathrm{L} / \mathrm{ml}$. Many novel control agents from botanicals previously have proven to be a significant potential mosquito killer as they are relatively safer, cost effective, less toxic and easily degradable.

The present study have shown repellent, and adulticidal activity might be due to the presence of phytochemicals constituents such as Hexadecanoic acid, Glucobrassicin, Ethanol, 2-(9-octadecenyloxy)(Z), Tridecanoic acid, 1,2,4-Trioxolane-2-octanoic acid 5-octyl-methyl ester, Ethanone, 1,1'-(1,4-dihydro-2,4,6-trimethyl-3,5-pyridinediyl) bis-, Pentetic Acid and 9-Hexadecenoic acid which may cause inhibition of poly (ADP-ribose) polymerase enzyme which is involved in the DNA repair in adult mosquito, alterations in the siphon and toxicity of prothoracic glands in instar larvae. Hexadecanoic acid, Tridecanoic acid and Glucobrassicin are natural insecticides and nematicides. Similarly Sargassum polycystum showed a lethal effect in mosquitocidal activity on Ae. aegypti and Cx. quinquefasciatus. Earlier reports showed the essential oil compounds Eucalyptol, Caryophyllene, Germacrene-D and a-humelene showed significant adulticidal activity whereas Cyclopentane, Hydrazinecarboxamide, Benzamide, Pentadecanoic acid, Cyclopentanone, Hexanedioic acid, 2-Hydroxy1-(Hydroxymethyl) ethyl ester and mono (2-ethylhexyl) ester showed larvicidal and repellent activity [10]. Comparing earlier authors evaluation our results revealed that the experimental Halophila ovalis extract was effective to mosquito vectors.

\section{Conclusion}

The structural elucidation of the seagrass Halophila ovalis extract showed the presence of most effective, unique chemical classes. The results as well as the significance of this preliminary investigation highlight the importance of Halophila ovalis as a novel source for natural insecticidal products. The structural elucidation of the Halophila ovalis extract throws light into the development of potential pesticide, insecticide and repellent cream at a large scale level for wider use for humankind. Further studies on identification of active compounds, toxicity and field trials are needed to recommend the active fraction of these plant extracts for development of eco-friendly chemicals of insect vectors.

\section{References}

1. Kuno $\mathrm{G}$ (1997) Factors influencing the transmission of dengue viruses. Gubler DJ, Kuno G, (eds) Dengue and Dengue Hemorrhagic Fever. New York.

2. Service MW (1997) Mosquito (Diptera: Culicidae) dispersal: the long and short of it. J Med Entomol 34: 579-588.

3. Hotez PJ, Remme JHF, Buss P, Alleyne G, Morel C, et al. (2004) Combating tropical infectious diseases: report of the disease control priorities in developing countries project. Clin Infect Dis 38: 871-878.

4. Pancharoen C, Kulwichit W, Tantawichien T, Thisyakorn U, Thisyakorn C (2002) Dengue infection: a global concern. J Med Assoc Thai 85 Suppl 1: S25-33.

5. Midega JT, Muturi EJ, Baliraine FN, Mbogo CM, Githure J, et al. (2010) Population structure of Anopheles gambiae along the Kenyan coast. Acta Trop 114: 103-108.

6. Murugan K, Mahesh Kumar P, Kovendan K, Amerasan D, Subrmaniam J et al (2012) Larvicidal, pupicidal, repellent and adulticidal activity of Citrus sinensis orange peel extract against Anopheles stephensi, Aedes aegypti and Culex quinquefasciatus (Diptera: Culicidae). Parasitol Res 111: 1757-1769.

7. Baranitharan M (2014) Mosquitocidal efficacies of medicinal plant of coleus aromaticus benth (lamiaceae) leaf extracts chikungunya vector, Aedes aegypt (linn.) (Diptera: Culicidae). Int J Curr Res Chem Pharma Sci 1: 61-67.

8. Rahuman AA, Bagavan A, Kamaraj C, Vadivelu M, Zahir AA, et al. (2009) Evaluation of indigenous plant extracts against larvae of Culex quinquefasciatus Say (Diptera: Culicidae). Parasitol Res 104: 6370-643.

9. Das NG, Goswami D, Rabha B (2007) Preliminary evaluation of mosquito larvicidal efficacy of plant extracts. J Vect Borne Dis 44: 145-148.

10. Ali MS, Ravikumar S, Beula JM, Anuradha V, Yogananth N (2014) Insecticidal compounds from Rhizophoraceae mangrove plants for the management of dengue vector Aedes aegypti. J Vector Borne Dis 51: 106-114.

11. Kovendan AK, Murugan K, Vincent S, Donald R (2012) Mosquito larvicida properties of Orthosiphon thymiflorus (Roth) Sleesen. (Family: Labiatae) against mosquito vectors, Anopheles stephensi, Culex quinquefasciatus and Aedes aegypti (Diptera: Culicidae). Asian Pacific J Tro Med 12: 299-305.

12. Ali MS, Ravikumar S, Beula JM (2012) Spatial and temporal distribution of mosquito larvicidal compounds in mangroves. Asian Pac J Trop Dis 2: 401-404.

13. Liu N, Xu Q, Zhu F, Zhang L (2006) Pyrethroid resistance in mosquitoes. Insect Sci 13:159-166.

14. Patra JK, Rath SK, Jena K, Rathod VK, Thatoi H (2008) Evaluation of antioxidant and antimicrobial activity of seaweed (Sargassum sp.) extract: A study on inhibition of Glutathione-S Transferase activity. Turkish J Bio 32: 119-125.

15. Ravikumar S, Abideen S, Ali MS, Selvam MB (2010) In vitro human sperm immobilizing activity of marine halophytes. J Pharm Res 4: 1291-1293.

16. Ermakova S, Sokolova R, Kim SM, Um BH, Isakov V (2011) Fucoidans from Brown Seaweeds Sargassum hornery, Eclonia cava, Costaria costata: Structura Characteristics and Anticancer Activity. Appl Biochem Biotechnol 164: 841-850.

17. Kannan S (2014) FT-IR and EDS analysis of the seaweeds Sargassum wighti (brown algae) and Gracilaria corticata (red algae) Int J Curr Microbiol App Sci 3 341-351.

18. Rodriguez-Bernaldo de Quiros A, Lage-Yusty MA, Lopez-Hernandez J (2010) Determination of phenolic compounds in macroalgae for human consumption. Food Chem 121: 634-638.

19. Davis TA, Volesky B, Mucci A (2003) A review of the biochemistry of heavy metal biosorption by brown algae. Water Research 37: 4311-4330.

20. Pham MN, Tan HTW, Mitrovic S, Yeo HHT (2011) A Checklist of the Algae of Singapore (2nd Edn). Raffles Museum of Biodiver Res 99.

21. Lim S, Ng P, Tan L, Chin WY (1994) Rhythm of the Sea: The Life and Times of Labrador Beach. Division of Biology, School of Science, Nan yang Technological University \& Department of Zoology, National University of Singapore.

22. WHO (2005) Guidelines for laboratory and field testing of mosquito larvicides Geneva. 